\section{PAGES-REDIE Fellowship Week}

\section{Bern, Switzerland, 12-16 July, 1999}

For the first time, seven young scientists from developing countries were able to spend a week at the PAGES office in Bern as part of a PAGES/START fellowship. The aim of the week at the PAGES IPO was to interact, share individual research findings, and establish links with PAGES scientists. The presentations represented a wide diversity of paleoscience, and are presented here within the context of three time periods: the last 500 years, the Holocene and the last 60,000 years.

\section{The last $\mathbf{5 0 0}$ years}

Multiproxy records of global climate have shown that the most dramatic warming of at least the last millennium has occurred during the last century. Therefore, high resolution studies covering the last few centuries are important in order to understand and predict global and regional climatic systems. Two case studies were presented which reflect changes during this period using very different techniques and in very different environments. The first case shows direct human interference in regional moisture balance over a specific region in southwest of India. The second shows oceanographic response to warming in the northeastern tropical Pacific.

The transformation of Anantapur (southwest India) from a once humid to a completely arid area in the last two centuries prompted an evaluation of climatic

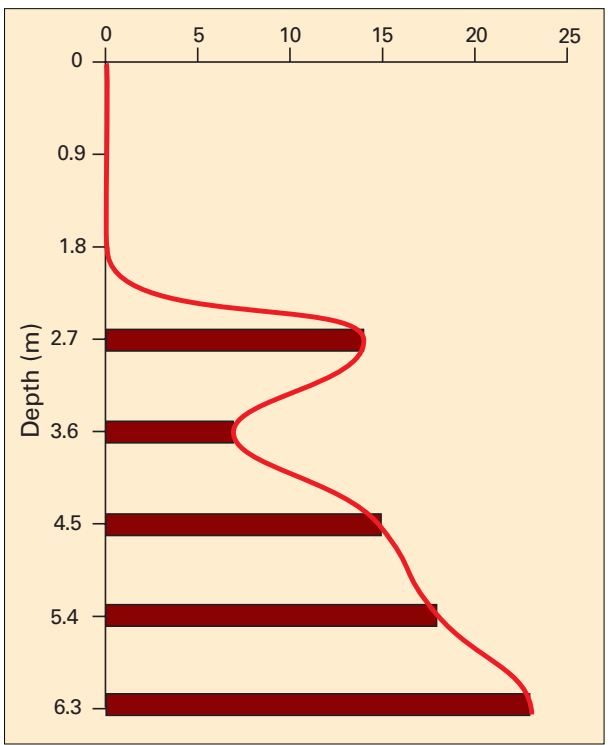

Figure a: Vertical variation of the pollen of tree taxa, as a percent of total pollen, in the Bukkapatnam tank, India. (P.J. Thomas) changes in the area. Being located in a rain shadow region of the Western Ghat mountains, this region receives less rainfall than any other location in the whole of South India. Rainfall records in the area show no specific trend, but an increase of $0.8^{\circ} \mathrm{C}$ in temperature has been observed over the last 50 years. Studies on sediment samples collected from the area point towards an abrupt change in the sediment deposition pattern in the last 200 years which can be attributed to drastic deforestation (figure a). This data is complemented by an extant historical inscription, dated 1416, which reads "We grant to you the tract of land bounded as follows ... in which you may cut down the jungle and form fields ...". The human impact on the local climate has been demonstrated in this study. However, better chronological control, as well as similar studies on sediments from the surroundings, should be carried out to improve understanding of processes involved in local environmental change.

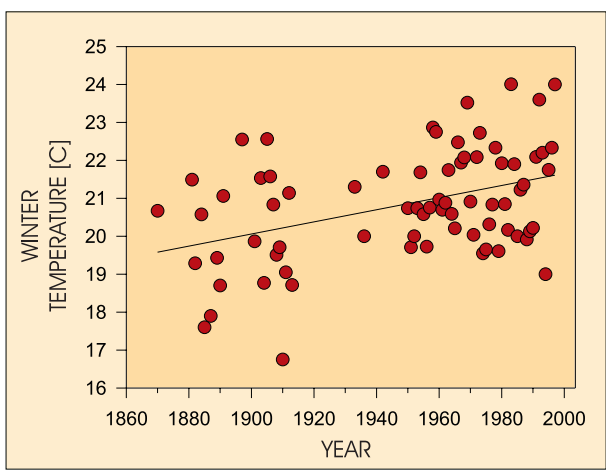

Figure b: Sea surface winter temperatures in La Paz basin, lower Gulf of California, during the last century. (G. Bernal; the authors gratefully acknowledge use of data from Release 1 of the COADS dataset).

In another context, records from laminated sediments from La Paz basin, lower gulf of California, indicate that sedimentation inside the basin has changed during recent centuries favoring accumulation of inorganic over organic Carbon. This could be explained by lower calcite dissolution, higher calcite fluxes or a combination of both in more recent times. During the last century, winter sea surface temperature of the area has increased (figure b). At the same time, the isotopic difference in $\delta^{18} \mathrm{O}$ between the foraminifera Pulleniatina obliquiloculata and Globigerina bulloides has increased, indicating

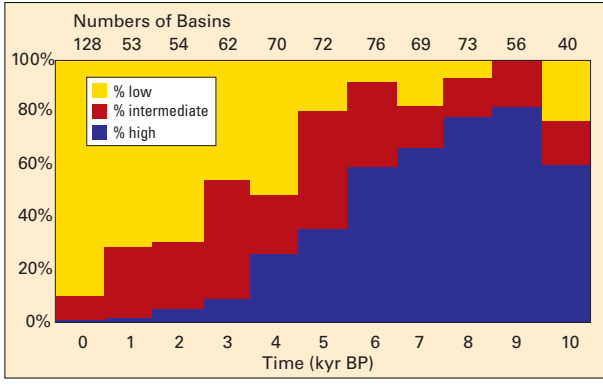

Figure c: Lake status variations during the last 10,000 years BP in Northern Hemisphere Africa. The histogram indicates the relative number of lakes with high, intermediate and low status in this area at each 1000 year interval. Changes in lake status (a measure of relative water depth or lake level) can be reconstructed from stratigraphic, sedimentological, geochemical and paleoecological data. For the Northern Hemisphere Africa, the lake status data show that conditions were generally wetter than today during the early and middle Holocene (the maximum of wetness occurred at about 9,000 yrs B.P); conditions became progressively drier after 5000 years B.P. (B. Damnati et al., in press)

a possible change towards more stratified conditions. This could support the hypothesis of ecological changes leading to more calcitic biogenic production. But benthic and planktonic foraminifera accumulation and a fragmentation index support the idea of changes in calcite dissolution. Other proxies for primary productivity could help improve our understanding of this marine environment.

\section{The Holocene}

Continental climate records were presented that indicate that the Holocene has been a climatically unstable period. Recent marine records from the SE Arabian Sea supporting this conjecture were also shown, with monsoon related oceanic processes being highly variable. Large scale changes in oceanic processes in this areas occurred even after 6000 years BP. Multi-proxy continental data from Africa (figure c) and the Indian subcontinent clearly indicate that the Holocene monsoon maximum occurred at around 9000 years BP, but recent high resolution investigations from North India suggest that the maximum occurred at around 6000 years BP. Moreover the extent of northward movement of the ITCZ during the mid Holocene is not well defined. Biological productivity proxies within the SE Arabian sea records reveal that the coupling between monsoon wind strength; mixed layer processes and surface productivity may have responded non-linearly in the past (figure d). 
For the late Holocene, differentiating the human impact from low amplitude climatic changes has been difficult, mainly due to the lack of disturbance indicators. To overcome this problem in the Ethiopian Rift Valley, charcoal and grass epidermal fragments have been used to show the effect of domestic grazing after 2000 years BP (not shown).

\section{The Last 60,000 years}

Preliminary results of terrestrial records from Yunnan (southwestern China) and deep sea records from the Sulu Sea were presented. Both areas are influenced by monsoon systems, primarily the Indian and East Asian monsoons respectively. The Western Pacific Warm Pool influences the atmospheric and hydrological conditions in the Sulu Sea. In Yunnan, terrestrial indicators from lacustrine deposits, e.g. total organic carbon, pollen content, magnetic susceptibility, and percentage calcium carbonate, show several warm/wet and cool/dry episodes in the interval from 58 to $32 \mathrm{ky} \mathrm{BP}$. These climatic changes are also observed in the record of lake level oscillations. The Sulu Sea high-resolution $\delta^{18} \mathrm{O}$ and $\mathrm{Mg} / \mathrm{Ca}$ records document apparently large, previously undetected millennial climate "events" during marine isotope stage (MIS) 3. Preliminary interpretation of $\delta^{18} \mathrm{O}$ and $\mathrm{Mg} / \mathrm{Ca}$ records suggests that these "events" are due in part to sea surface temperature and at least partly the result of changes in sea surface salinity in the Sulu Sea.

The observed terrestrial and marine climatic changes seem to be related in a simple manner with $\delta^{18} \mathrm{O}$ depletion maxima and $\mathrm{Mg} / \mathrm{Ca}$ maxima in marine records correlating with warm/wet episodes in the continental records. Correlation in this sense can be observed not only during the time of MIS 3, but also in the younger records (e.g., Last Glacial Maximum, Younger Dryas). Improvement of chronological control, especially beyond the range of radiocarbon dating is necessary. Further correlation of marine and terrestrial records could help shed light on the mystery of land-ocean linkages, in this case the link between the Indian and the East Asian monsoons and the Western Pacific Warm Pool.

\section{Conclusions and Recommendations}

A discussion session was held to provide recommendations for how PAGES

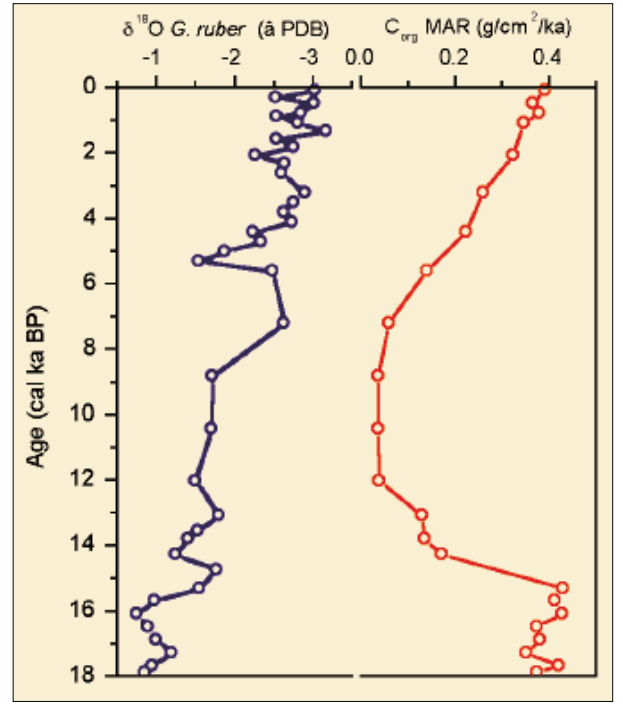

Figure d: Stable isotope record of planktonic foraminifera and mass accumulation rates (MAR) of organic carbon in a sediment core off SE Arabian Sea (M. Thamban et al., in press)

can best continue to support the work of young scientists from developing countries. The following recommendations were agreed upon:

- provide access to recent, updated data sets

- maintain a direct e-mail list

- facilitate access to modern equipment through opportunity announcements and by providing access to second hand equipment

- hold more workshops in developing countries

- facilitate submission of international proposals to national funding agencies

- lobby for increased funding of paleoscience, especially in developing countries

\section{G. Bernal, CICESE, Mexico; gbernal@cicese.mx B. Damnati, Abdelmalek Essaadi University, Morocco; bdamnati@hotmail.com}

S. Dannenmann, New York State University, USA; steffi@atmos.albany.edu

M.U. Монамmed, Addis Ababa University, Ethiopia; mohammed_umer@hotmail.com

A. Mulock-Houwer, University of Cape Town, South Africa; houwer@egs.uct.ac.za

M. Thamban, National Institute of Oceanography, India; meloth@csnio.ren.nic.in

P.J. THOmas, Andhra University, India; puthusery@hotmail.com

Y. YIN, University of Geosciences, China; yinyong@sky.cugb.edu.cn

For full references please consult www.pages.unibe.ch/ publications/newsletters/ref993.html

\section{PEP III at the XV INQUA Congress}

\author{
Durban, South Africa, 3-11 August 1999
}

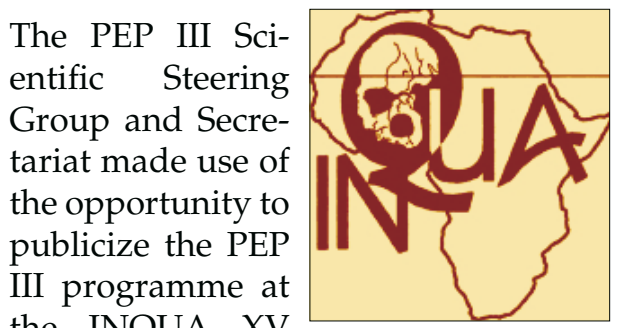
the INQUA XV

Congress by convening a thematic poster and a workshop session on past climate variability through Europe and Africa. The 90-minute poster session attracted a mix of scientists and $\mathrm{PhD}$ students from paleocommunities across the transect whose excellent presentations reflected the highest quality of research. The session highlighted a broad range of climate reconstructions for both timestreams using a variety of archives and proxies in both individual projects and larger collaborative programmes. Following an introductory delivery by Françoise Gasse, presentations of 6 generic posters outlined details of large multinational programmes from across the transect such as EDDI (European Diatom Database Initiative) and GASPAL (Groundwater as a continental indicator of past climatic conditions). The popularity of this session (28 posters were presented) forced us to divide the remaining hour into a series of parallel sessions according to climatic region. The posters received a lot of attention at the Congress, fulfilling our objective to publicize PEP III to a wider audience as well as to spread awareness of related projects amongst those already involved. It also highlighted existing gaps in paleoclimate studies with respect to both climatic region and to methodologies. In particular, paleoclimate science in Eastern Europe was poorly represented.

The workshop and business meetings focused on ways to alleviate problems encountered by African scientists within PEP III. PAGES funded three Africans to attend INQUA: Chiori O.C. Agwu (University of Nigeria), Cheikh Gaye (formerly of Cheikh Anta Diop University, Senegal, now IAEA, Vienna) and Daniel Olago (University of Nairobi, Kenya). PAGES also contributed continued on page 18 